\title{
MONITORING THE SURFACE SUBSIDENCE OF HANDAN CITY USING SENTINEL-1A IMAGES AND SBAS-INSAR TECHNOLOGY
}

\author{
Guoman Huang ${ }^{1,2}$, Huan Chen ${ }^{1,2}$,, $\mathrm{Xi} \mathrm{Li}^{1,2}$, Guoqi Cheng ${ }^{1,2}$, Zhigang Yu ${ }^{1,2}$, Haiyan $\mathrm{Gu}^{2}$ \\ ${ }^{1}$ College of Geomatics, Shandong University of Science and Technology, Qingdao 266590, China - ( huang.guoman, chcx0329, \\ lix_2018,cgq66six) @163.com, yu_zg@sdust.edu.cn \\ ${ }^{2}$ Key Laboratory of Geo-Informatics of State Bureau of Surveying and Mapping, Chinese Academy of Surveying and Mapping,
} 100830 Beijing, China - guhy@ casm.ac.cn

Commission III, WG III/3

KEY WORDS: Sentinel-1, SBAS-InSAR, land subsidence, Handan

\begin{abstract}
:
The Sentinel-1 data is currently the latest free SAR data and is well suited for land subsidence monitoring based on InSAR technology due to its 6-day revisit cycle. In this paper, the urban area and surrounding areas of Handan City are used as research areas, and 29 scences of S1A data (December 2017 - December 2018) was used for time series SBAS processing. The results shows that the surface cumulative deformation ranged from -42 to $30 \mathrm{~mm}$ in most regions of Handan City. The maximum settlement is $69 \mathrm{~mm}$, which is near the Hankuang Group Julong Company. The areas where the settlement is obvious include Wu'an City, Daishan Village, Dashe Town, Zhangxibao Town, Baijia Street, Dongxingtai Village, Gaonan Village and Hankuang Group Julong Company. Slightly elevated in the southeast of Handan City.
\end{abstract}

\section{INTRODUCTION}

With the development of society, economic prosperity, largescale construction of transportation facilities and houses, continuous exploitation of mineral resources and overexploitation of groundwater caused environmental degradation. A series of environmental geological problems have arisen, which have led to the development of disasters such as landslides, collapses, slope instability and land subsidence. Geological disasters occur in many types, large quantities, and great hazards, which have a major impact on surrounding buildings and personal safety, and the damage caused to the environment is difficult to recover(Zhou, 2017a).

Land subsidence is one of the major geological disasters in Handan City. It has a large amount of settlement and a wide range of spreads, and induces geological disasters such as landslides, ground fissures and ground subsidence. Interferometric synthetic aperture radar (InSAR) technology is a popular ground subsidence monitoring method in recent years. Compared with traditional ground subsidence monitoring methods, it has the advantages of high monitoring accuracy (up to millimeter level), wide coverage, high operating efficiency, low cost, and streamlined data processing(Hanssen, 2001). It has become one of the hotspots of research in the world.

Conventional InSAR techniques are often limited by the effects of spatiotemporal mismatch and atmospheric delay(Zebker, 1992a), which makes their deformation detection accuracy low. Small baseline subset (SBAS) InSAR technology can effectively overcome the spatial and temporal de-correlation of differential interferometric synthetic aperture radar (D-InSAR), and can obtain the settlement of time series. Compared with persistent scatterer (PS) InSAR technology, it reduces the number of SAR images required, and the calculation speed is faster(Zhu, 2017a). A large number of scholars have verified that SBAS-InSAR technology has high monitoring accuracy in urban settlement monitoring, up to millimeter level (Wang, 2015a; Xie, 2015a).

This paper uses SBAS technology and S1A data to monitor the surface subsidence of Handan City during the period from 2017.12 to 2018.12. Monitoring and analyzing the development law and spatial distribution characteristics of land subsidence in Handan City, providing the government with the basis for control and governance.

\section{STUDY AREA AND EXPERIMENTAL DATA}

\subsection{Over of The Study of Area}

In this paper, choosing Handan City as a research area, The research area of this paper is the urban area of Handan City as shown in Figure 1. The range of research area is about $50 \mathrm{~km} * 60 \mathrm{~km}$. It is located between $114^{\circ} 03^{\prime}-40^{\prime}$ east longitude and $36^{\circ} 20^{\prime}-44^{\prime}$ north latitude.

The terrain is high in the west and low in the east. The height difference is very large and the types of landforms are complex and diverse. The climate of the study area is typical of temperate semi-humid continental monsoon climate. The study area has a variety of mineral resources, with coal and iron ore accounting for the majority. The principal industry in Handan City is agriculture, and nearly $60 \%$ of agricultural irrigation water is groundwater.

\footnotetext{
* Corresponding author at: College of Geomatics, Shandong University of Science and Technology, Qingdao.

E-mail address: chcx0329@163.com.
} 


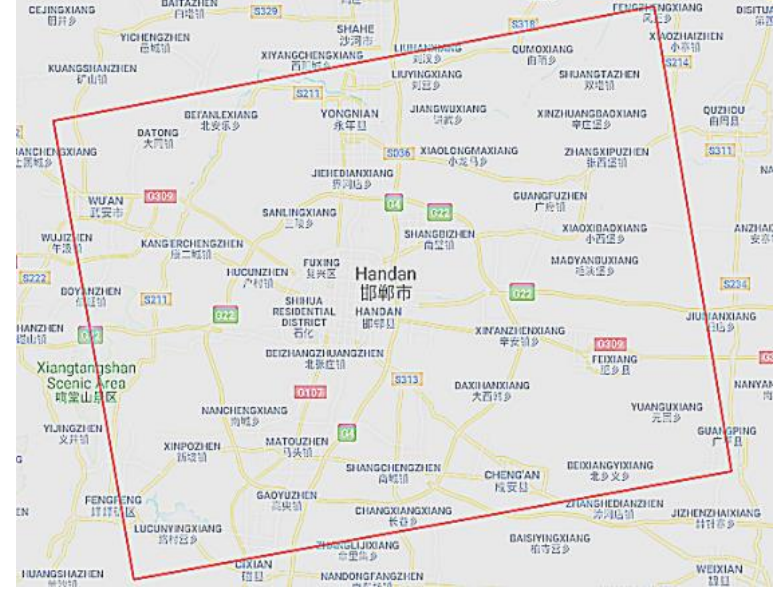

Figure 1. Location of study area

\subsection{Experimental Data}

Sentinel-1A is the first earth observation satellite of the ESA Copernicus program with a C-band SAR, which is currently well-perceived SAR satellite data and is very suitable for InSAR surface deformation monitoring. The IW mode has a spatial resolution of $5 \mathrm{~m} \times 20 \mathrm{~m}$ and an image width is $250 \mathrm{~km}$. which is suitable for InSAR high-precision surface deformation monitoring (Zhang, 2017a). This paper uses 29 scences of Sentinel-1A data and the corresponding precision orbit file during the period from 2017.12.15 to 2018.12.10, and the selected external reference DEM is SRTM data at a resolution of 30 meters. See Table 1 for details of the experimental data.

\begin{tabular}{|c|c|c|c|}
\hline $\begin{array}{l}\text { Serial } \\
\text { number }\end{array}$ & $\begin{array}{l}\text { Data } \\
\text { source }\end{array}$ & $\begin{array}{l}\text { Image } \\
\text { date }\end{array}$ & $\begin{array}{l}\text { Orbit } \\
\text { number }\end{array}$ \\
\hline 1 & S1A & 20171215 & 40 \\
\hline 2 & S1A & 20171227 & 40 \\
\hline 3 & S1A & 20180108 & 40 \\
\hline 4 & S1A & 20180120 & 40 \\
\hline 5 & S1A & 20180201 & 40 \\
\hline 6 & S1A & 20180213 & 40 \\
\hline 7 & S1A & 20180225 & 40 \\
\hline 8 & S1A & 20180309 & 40 \\
\hline 9 & S1A & 20180321 & 40 \\
\hline 10 & S1A & 20180402 & 40 \\
\hline 11 & S1A & 20180414 & 40 \\
\hline 12 & S1A & 20180426 & 40 \\
\hline 13 & S1A & 20180508 & 40 \\
\hline 14 & S1A & 20180601 & 40 \\
\hline 15 & S1A & 20180613 & 40 \\
\hline 16 & S1A & 20180625 & 40 \\
\hline 17 & S1A & 20180707 & 40 \\
\hline 18 & S1A & 20180719 & 40 \\
\hline 19 & S1A & 20180731 & 40 \\
\hline 20 & S1A & 20180812 & 40 \\
\hline 21 & S1A & 20180824 & 40 \\
\hline 22 & S1A & 20180905 & 40 \\
\hline 23 & S1A & 20180917 & 40 \\
\hline 24 & S1A & 20180929 & 40 \\
\hline 25 & S1A & 20181011 & 40 \\
\hline 26 & S1A & 20181104 & 40 \\
\hline 27 & S1A & 20181116 & 40 \\
\hline 28 & S1A & 20181128 & 40 \\
\hline 29 & S1A & 20181210 & 40 \\
\hline
\end{tabular}

Table 1. shows the detailed parameters of the selected data.

\section{SBAS TIMING ANALYSIS METHOD}

\subsection{Principles of SBAS-InSAR Technology}

SBAS-InSAR is an InSAR time series method with multiple master images(Berardino, 2002a). This technology is mainly used for deformation monitoring in the following situations: low image resolution and large research area. The technical principle is to generate a series of time series interferogram sets of different master images by freely combining image pairs with short time-space baselines, and then use a matrix singular value decomposition (SVD) method to jointly solve multiple short baseline sets. In this way, the problem of time discontinuity caused by too long a space-time baseline between data sets can be overcome, the time resolution of the monitoring is improved, and the surface deformation information of the research area over the entire observation period is obtained. SBAS-InSAR technology overcomes the shortcomings of PS-InSAR technology because of the poor coherence of some interferograms caused by selecting a pair of images as common main images, and reduces the demand for SAR data, and the computational efficiency is high(Zhou,.2017a).

\subsection{Data Processing}

In this paper, S1A data and SBAS-InSAR technology are used to monitor the surface deformation of Handan City.The software used for data processing is Gamma and Giant. The data processing flow is shown in the figure 2 .

The main steps are as follows:

(1)Data preprocessing: Import S1A data into Gamma software, convert raw data into Gamma internal format, and add precision track files.

(2)SAR image co-registration :The image of 20171215 is selected as the super master image, and other images are registered to it. The registration accuracy requirement is less than 0.001 pixels to eliminate the phase jump of the burst azimuth(Wu, 2016a). Crop the study area after registration.

(3)Baseline estimate: There were many vegetations in the study area. In order to avoid the effects of time incorrelation, the time baseline threshold was set to 80 days and the maximum space baseline was set to 300 meters. In this case, 130 interference pairs are generated.

(4)Conventional D-InSAR processing : Azimuth spectrum deramping, Simulated topographic phases, formation of interferograms, phase filtering, coherence calculation, phase unwrapping. In the step of interferogram filtering, the filter coefficient is 0.3 . In the step of phase unwrapping, the coherence threshold is 0.3 .

(5)Geocoding: The phase unwrapped results and coherence files are resampled into the GCS-WGS-84 coordinate system. Check the original interferograms, the filtered interferograms, the coherence coefficient plot, and the phase unwrapped interferograms. Interferograms which phase unwrapping is incorrect and severely affected by the atmosphere are eliminated. Finally, 113 interferograms were left to participate in the SBAS solution.

(6)The selected interferograms is calculated using the Giant software for SBAS time series. The coherence threshold set in the SBAS time series processing is 0.3 , and the filter coefficient threshold is 0.3 . 


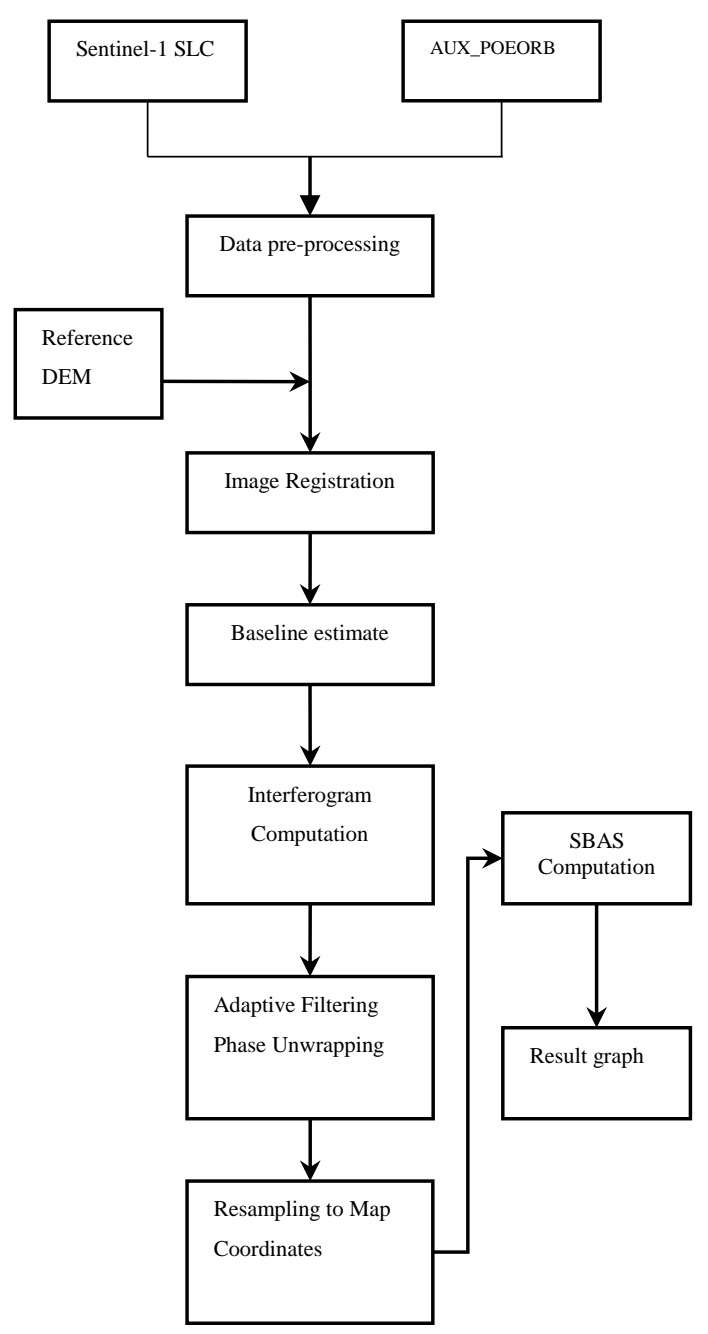

Figure 2. Flowchart of SBAS algorithm based on TOPS SAR

\section{RESULTS AND ANALYSIS}

The spatial-temporal baseline distribution obtained in this experiment is shown in Figure 3. The cumulative deformation obtained from the SBAS timing processing are shown in Figure 4.

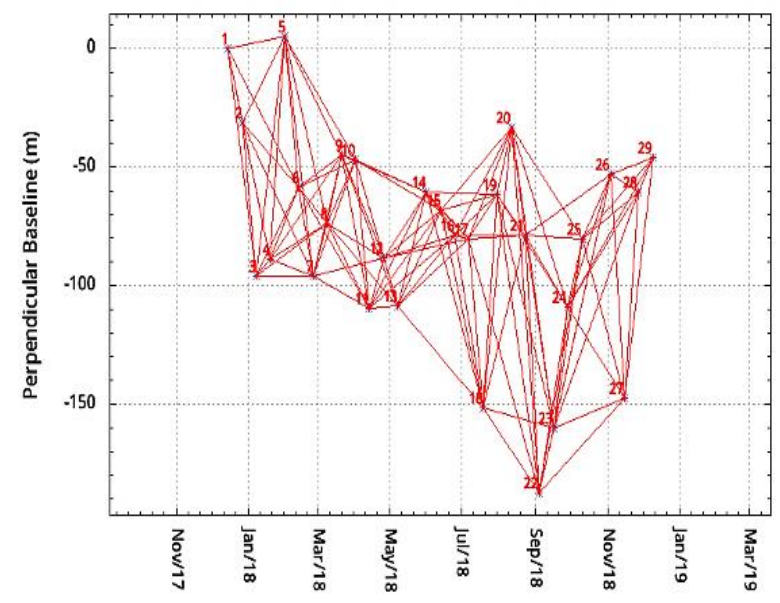

Figure 3. Spatial-temporal baselines of interferograms

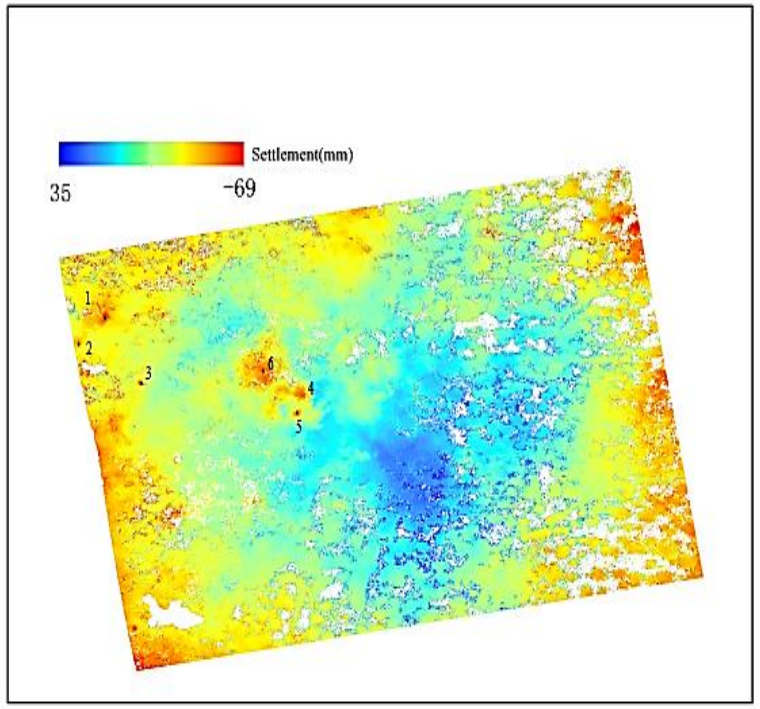

Figure 4. Cumulative deformation of the study area

The research shows that surface cumulative deformation of most regions in Handan City is in the range of -42 to $30 \mathrm{~mm}$. About $50 \%$ of the area is converted into surface subsidence, and the area where the settlement exceeds $10 \mathrm{~mm}$ accounts for about $15 \%$. The maximum settlement is $69 \mathrm{~mm}$, which is near the Hankuang Group Julong Company. The areas where the settlement is obvious are Wu'an City, Daishan Village, Dashe Town, Zhangxibao Town, Baijia Street, Dongxingtai Village, Gaonan Village and Hankuang Group Julong Company. Slightly elevated in the southeast of Handan City. In order to understand in more detail the settlement of the city during the monitoring period, the 6 points from 1 to 6 were selected in the study area, and the time series cumulative deformation of the 6 points along the line of sight (LOS) was plotted. As shown in Figure 5:
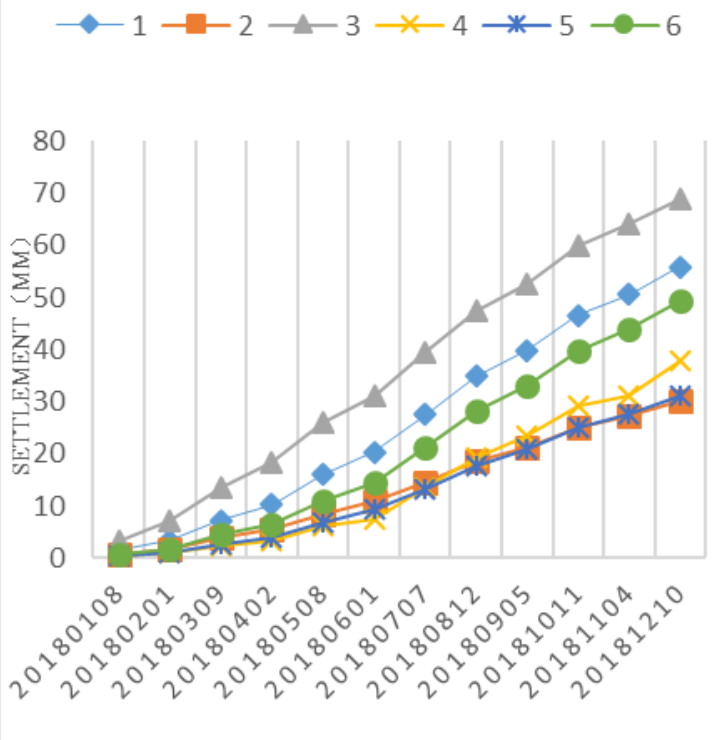

Figure 5. Deformation time series of the ground points 
Point 1 is located in Pianshan Village, as shown in Figure 6(a).Point 2 is located in Wu'an City, as shown in Figure 6(b). Point 3 is located near the Hankuang Group Julong Company, as shown in Figure 6(c). The company is mainly engaged in coal mining, washing, and sales of coal products. Point 4 is located in Dongxingtai Village as shown in Figure 6(d). Point 5 is located at Baijia Street, as shown in Figure 6(e) and .Point 6 is located in Gaonan Village, as shown in Figure 6(f).

Figure 5 shows that the settlement near Hankuang Group Julong Company is the largest, followed by PianshanVillage. This may be because the industrial water consumption of the Pianshan
Village and Hankuang Group Julong Company is large, and the industrial water is groundwater, so the ground subsidence is large in these two places. The remaining four places are dense residential areas with relatively small settlements.

It should be noted that the deformation obtained by SBAS time series analysis is relative to the reference point, which is located at the airport. Although the reference point chosen here is at the airport, there is no guarantee that it will be absolutely stable or there may also be subsidence. In the next step, the ground measured data can be considered to further correct the settlement results.

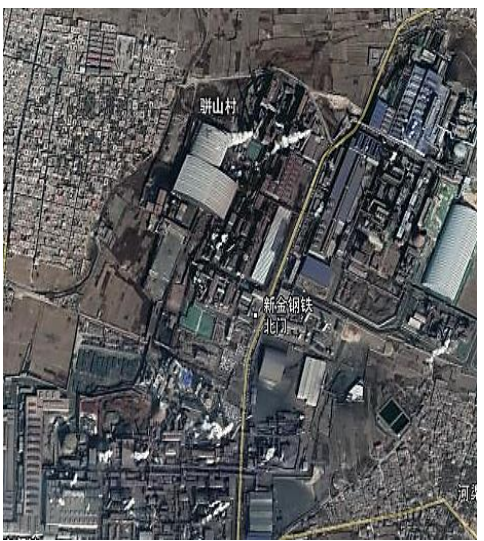

(a)

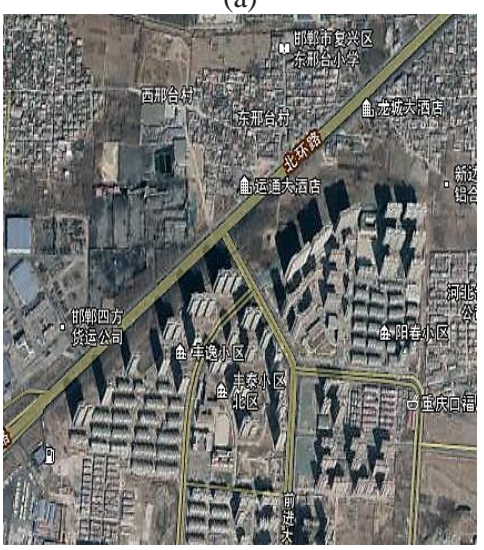

(d)

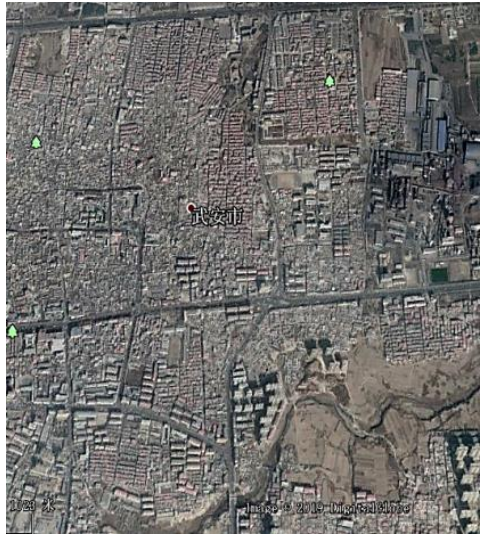

(b)

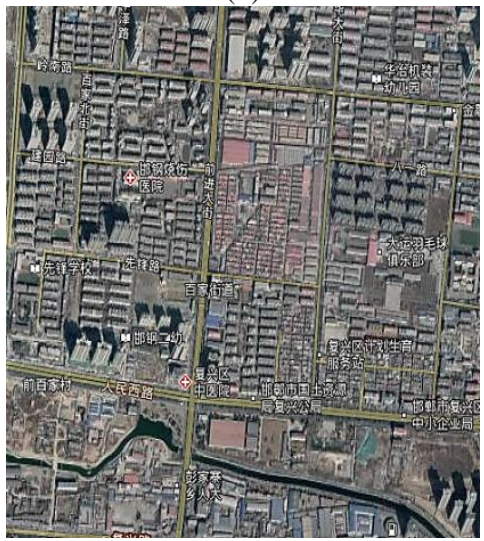

(e)

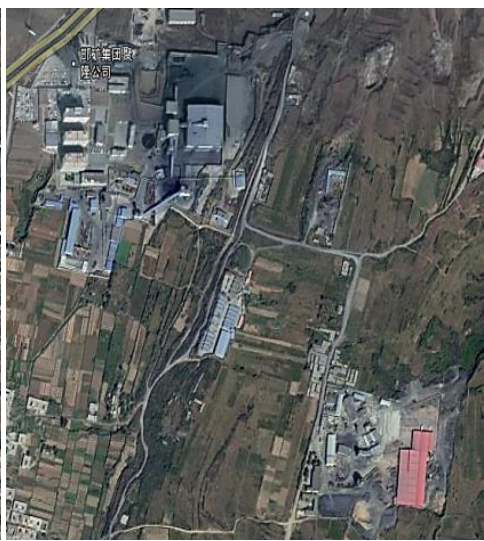

(c)

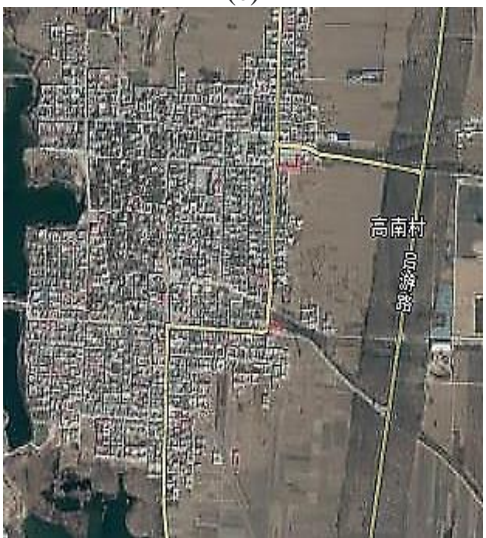

(f)

Figure 6. Actual ground conditions

\section{ACKNOWLEDGEMENTS}

This work was supported in part by The National Key Research and Development Program of China (No. 2018YFF0215303) and the basic plan of science and technology of Surveying and mapping (No. 2018KJ0103).

\section{REFERENCES}

Berardino P., 2002a. A new algorithm for surface deformation monitoring based on small baseline differential SAR interferograms. IEEE Transactions on Geoscience and Remote Sensing, 40(11), 2375-2383.
Zhou H.Y., 2017a. Land Subsidence Monitoring and Analyzing of Cangzhou Area. Bulletin of Surveying and Mapping, (07), 89-93.

Zhu J.J., 2017a. Research Progress and Methods of InSARforDeformation Monitoring. Journal of Geodesy and Geoinformation Science, 46(10), 1717-1733.

Zhang Y.M., 2017a. Monitoring Xi'an Land Subsidence Using Sentinel-1 Images and SBAS-InSAR Technology. Bulletin of Surveying and Mapping, (04), 93-97.

Hanssen R.F., 2011. Radar Interferometry : Data Interpretation and Error Analysis. Springger, Netherlands, 6768. 
Xie R.G., 2015a. Research of Using SBAS to Monitor Ground Subsidence. Bulletin of Surveying and Mapping, (08), 70-73.

Wang H.Y.,2015a. Monitoring Surface Deformation Using SBAS-InSAR Technology. Journal of Geodesy and Geoinformation Science, 40(10), 123-127.

Wu W.H., 2016a. Interferometric Processing of TOPS Mode for Sentinel - 1A. Bulletin of Surveying and Mapping, (02), 42-45.

Zebker H A., 1992a. Decorrelation in interferometric radar echoes. IEEE Transactions on Geoscience and Remote Sensing, 30(5), 950-959. 